\title{
Effect of Aging under Strain on the Physical Properties of Polyester-Urethane Elastomer
}

\author{
Y. W. DenG, ${ }^{*}$ T. L. Yu, ${ }^{* \dagger}$ and C. H. Ho** \\ * Department of Chemical Engineering, Yuan-Ze Institute of Technology, \\ Nei-Li, Taoyuan, Taiwan 32026 \\ ** Department of Chemical Engineering, Lung Hwa Junior College of Engineering, \\ Kwei-Shan, Taoyuan, Taiwan 33327
}

(Received June 1, 1994)

\begin{abstract}
The mechanical, degradation, and related thermal properties of segmented polyster-urethane elastomers which were aged under strain in three different environments $\left(25^{\circ} \mathrm{C}\right.$ in air, $85^{\circ} \mathrm{C}$ in air, and $85^{\circ} \mathrm{C}$ in water) were investigated by stress-strain measurements, DSC, and FTIR. From the stress-strain measurements, it showed that the polyester-urethane samples aged under a high prestrain, particularly at high temperature, resulted in decreases of the initial slope, and stress and elongation at break. The behavior of stress-strain curves also showed that aging the polyester-urethane at a higher prestrain and a higher temperature leaded the urethane elastomer to be more brittle. Morphological changes which were induced in the segmented elastomer by aging under strain were investigated by DSC in terms of the glass transition temperature of the soft segments, the melting temperature of the hard segments, and the heat of fusion of the crystalline hard segments. FTIR measurements indicated the degradation of the ester $\mathrm{C}-\mathrm{O}-\mathrm{C}$ bond during aging at high strain, especially in the water. Based on the DSC and FTIR studies, the behavior of the stress-strain measurements of the aged urethane elastomers was explained.
\end{abstract}

KEY WORDS Polyurethane / DSC / FTIR / Stress-Strain / Aging /

The segmented polyester-based urethanes are thermoplastic elastomers with high elongation characteristics, along with typical properties of plastics such as modulus, strength, and processibility. It is generally agreed that the unique mechanical properties of polyurethanes, as compared to other types of elastomers, are predominantly the result of a two-phase morphology. ${ }^{1,2}$ The polyester based urethanes consist of an aromatic diisocyanate with a glycol chain extender as the hard segment and a low molecular weight aliphatic polyesters as the soft segment. They are considered to be linear segmented block copolymer, made up of alternating hard and soft block segments. Compositional variables and processing conditions are known to affect the degree of phase segregation, phase mixing, hard segment domain organization, and subsequent polyurethane properties. $^{2-4)}$ Depending on the relative incompatibility of the hard and soft segments, phase segregation will occur during processing and postcure annealing. The effects of polyurethane composition and structure on the resultant properties has been investigated by several researchers. ${ }^{5-20}$ These studies have been concentrated on model compounds based on aromatic dissocyanates, such as toluene diisocyanate (TDI $)^{5-6}$ or diphenyl methane dissocyanate (MDI). ${ }^{5-8}$ The phase segregation of hard and soft segment domains have been demonstrated by: small and wide angle X-ray scattering, ${ }^{9-12}$ differential scanning calorimetry, ${ }^{9-16}$ infrared spectroscopy, ${ }^{16-18}$ and mi-

† To whom all correspondence should be addressed. 
croscopy. ${ }^{19-20}$

Various methods have been used to study hydrolytic exposure of urethane elastomers in an unstressed state. Several researchers immersed the elastomers in water at temperatures between $50-100^{\circ} \mathrm{C}^{22-25}$ Other workers investigated the urethane elastomers above water at $70-100 \%$ relative humility and at the same temperature range. ${ }^{22-24}$ One of the most comprehensive studies were conducted by Athey $^{21}$ on thermoplastic elastomers. The experimental results indicated that the polyether-based urethanes are less easily hydrolyzed than the polyester-based urethanes.

The effect of stress on the morphology of urethane elastomers has been reported by several workers. Based on small angle X-ray scattering data, Desper ${ }^{26}$ deduced the breakup of the hard segment phase into smaller domains and associated this process in part to the manifestation of mechanical hysteresis. Infrared dichroism experiments ${ }^{27-29}$ have shown that segmented polyurethane undergo some degree of irreversible orientation, especially of the hard segments, at large strains. X-ray studies $^{30,31}$ have confirmed the process of strain induced orientation and crystallization in polyurethanes. For many of these materials strain-induced crystallization of the soft segment matrix could be largely irreversible ${ }^{32-34}$ and lead to permeanent deformation and a noticeable hysteresis effect. Once crystallization has occurred, the polymer matrix might become brittle. Subsequent energy placed into the system leads to the disruption of the crystallinity inside the soft segment, ${ }^{32}$ and causes crazing, bond breaking, and eventually, the failure of the polymer as a tensile break. Wang $^{32}$ and others ${ }^{33-35}$ have shown that, for polyether polyurethane elastomers, both the hard segment and soft segment contents are key to determining the material's mechanical hysteresis response.

In this work, the physical aging of polyurethane elastomer was proceeded in three different environments $\left(25^{\circ} \mathrm{C}\right.$ in air, $85^{\circ} \mathrm{C}$ in air, $85^{\circ} \mathrm{C}$ in water) for two days under various strain states. Stress-strain as well as DSC and FTIR measurements of these aged samples were conducted to study the effect of strain in these environments on the mechanical properties and morphology of polyester based urethane elastomers. Attempt has been made to correlate the stress-strain behavior and the morphological changes induced upon stretching of the materials.

\section{EXPERIMENTAL}

\section{Materials}

Poly(tetramethylene adipate) glycol (PTAd) was synthesized from butanediol and adipic acid with an $\mathrm{OH} / \mathrm{COOH}$ ratio of $1.3 / 1.0$. Thus, the polyesters had an acid number of $3 \mathrm{mg}$ $\mathrm{KOH}$ perg, and the molecular weight $M_{n}$ of the polyester determined by GPC (Waters model 746 GPC with $\mu$-styragel columns of pore sizes $500^{\circ} \AA, 10^{3} \AA$, and $10^{4} \AA$, and a RI detector) was found to be 2010 with a dispersion of $M_{w} / M_{n}=1.80$ at $25^{\circ} \mathrm{C}$. Tetrahydrofuran (THF) was used as the mobile phase, and narrow MWD polystyrene standards (Aldrich Chemical Co.) were used in a linear calibration. The polyurethane elastomers were synthesized randomly from PTAd, diphenylmethane-4,4'diisocyanate (MDI), and 1,4-butanediol (BDO) with a molar ratio of 1.5/7.1/5.5 in the $N, N$-dimethyl formamide (DMF) solvent. The reaction proceeded at $85^{\circ} \mathrm{C}$ for about $1 \mathrm{~h}$. Before polymerization, PTAd, BDO, and $\mathrm{DMF}$ were distilled at $70^{\circ} \mathrm{C}$ under vacuum for $1 \mathrm{~h}$ to remove moisture. MDI was used as it received without further purification. The final polyurethane contained $57 \mathrm{wt} \%$ of PTAd. In order to identify the DSC thermal transition and endotherms of the soft and hard segments of aged polyurethanes, the high molecular weight pure soft segment PTAd $\left(M_{n}=1.8 \times\right.$ $10^{4}$, and $\left.M_{w} / M_{n}=2.1\right)$ and pure hard segment polymer were synthesized. The high molecular weight PTAd was synthesized from butanediol and adipic acid with an $\mathrm{OH} / \mathrm{COOH}$ mole ratio 
of $1.05 / 1$, and the pure hard segment polymer was synthesized from BDO and MDI with a $\mathrm{OH} / \mathrm{NCO}$ ratio of $1 / 1$.

\section{Sample Preparation}

Polyurethane films were compression-molded at $180^{\circ} \mathrm{C}$ on a press (Tien Fa Co., Taiwan, R.O.C.) followed by cooling at an ambient temperature and environment. Test specimens were cut in the shape of a dumbell (ASTM D1708-66). These specimens were first elongated to each of the four designated stretching ratios $(0.0 \%, 20 \%, 200 \%$, and $400 \%)$ using an Instron Tensile Tester with a strain rate of $5.0 \mathrm{~cm} \mathrm{~min}{ }^{-1}$. The specimens were kept stretched and were aged in each of the three environments: (1) $25^{\circ} \mathrm{C}$ in air for 2 days; (2) $85^{\circ} \mathrm{C}$ in air for 2 days; (3) $85^{\circ} \mathrm{C}$ in water for 2 days. After the scheduled time, specimens were unloaded and removed from the environment. All the specimens were then equilibrated to the ambient conditions before testing. The residual strains for samples with various prestrains and aged under three different environments are shown in Table $I$.

Film for infrared analysis were cast directly onto a $\mathrm{NaCl}$ plate from dilute polymer solutions $\left(0.4 \mathrm{mg} \mathrm{ml}^{-1}\right)$, prepared by dissolving the treated samples in DMF solvent, and dired

Table I. Residual strain of PU aged in various environments

\begin{tabular}{cc}
\hline Prestrain & Residual strain \\
$\%$ & $\%$ \\
\hline $25^{\circ} \mathrm{C} /$ air $/ 1$ days & \\
20 & 3.9 \\
200 & 56.5 \\
400 & 115.3 \\
$85^{\circ} \mathrm{C} /$ air $/ 2$ days & \\
20 & 12.1 \\
200 & 148.7 \\
400 & 302.3 \\
$85^{\circ} \mathrm{C} /$ water $/ 2$ days & \\
20 & 12.8 \\
200 & 161.5 \\
400 & 307.7 \\
\hline
\end{tabular}

under vacuum to remove the solvent completely.

Samples cut from treated polyurethane elastomers with a weight range of $6.0-10.0 \mathrm{mg}$ were used for DSC scan studies.

\section{Mechanical Experiment}

Stress-strain curves of aged polyurethane samples were accomplished on an Instron Universal Materials Testing Machine at $25^{\circ} \mathrm{C}$. The samples were subjected to a deformation rate of $5.0 \mathrm{~cm} \mathrm{~min}^{-1}$ for the tension experiments. The load cell used was first calibrated, and it was found that the load remained constant within the range of experimental error. Typically, each analysis was carried out on a minimum of five samples and the average values were reported.

\section{Infrared Analysis}

A Fourier Transform IR Spectrophotometer (Perkin Elmer 1725X) was used in this investigation. All the spectra were taken at room temperature. Substraction of IR spectra was done using a reference peak at $1410 \mathrm{~cm}^{-1}$ band, due to thermally stable C-C stretching mode of the benzene ring.

\section{DSC Study}

Differential scanning calorimetry was carried out on a Du Pont 910 DSC. The heating rate was $20^{\circ} \mathrm{C} \mathrm{min}^{-1}$ for the temperature range $-100-240^{\circ} \mathrm{C}$.

\section{RESULTS AND DISCUSSION}

\section{Stress-Strain Measurements}

The morphology of phase segregation of these urethane elastomers is the key determining their stress-strain behavior. ${ }^{1,2}$ Test specimens were subjected to a series of strains under different environments $\left(25^{\circ} \mathrm{C}\right.$ in air, $85^{\circ} \mathrm{C}$ in air, and $85^{\circ} \mathrm{C}$ in water) for two days. Typical stress-strain curves of the aged urethane samples with $0 \%$ prestrain at $25^{\circ} \mathrm{C}$ in air, $20 \%$ prestrain at $85^{\circ} \mathrm{C}$ in air, and $200 \%$ prestrain 
at $85^{\circ} \mathrm{C}$ in water are shown in Figure 1 . The stress-strain curves for polyurethane, after having been prestrained to $400 \%$ elongation, and aged in three environments $\left(25^{\circ} \mathrm{C}\right.$ in air, $85^{\circ} \mathrm{C}$ in air, and $85^{\circ} \mathrm{C}$ in water) for 2 days, are shown in Figure 2. Prior to obtaining those stress-strain curves, the prestrained samples were relaxed in air and dried. The effects of 2 days of aging in water and air with various prestrains $(0 \%, 20 \%, 200 \%$, and $400 \%)$ on the

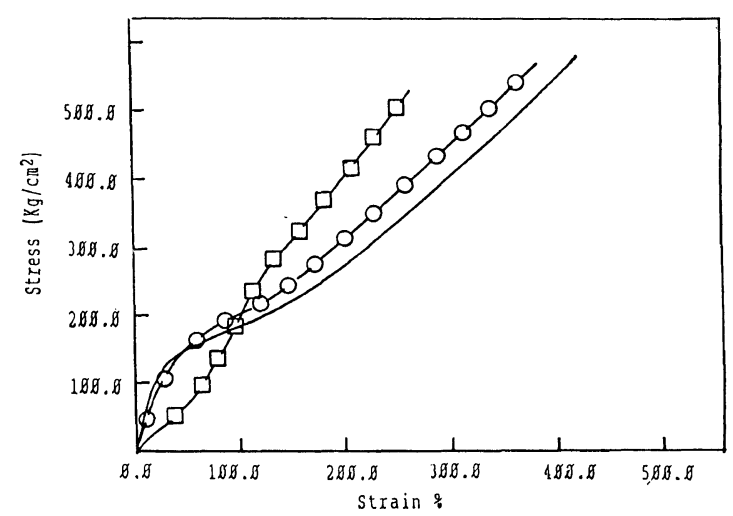

Figure 1. Stress-strain curves of aged polyurethanes. (-) Aged under $0 \%$ prestrain at $25^{\circ} \mathrm{C}$ in air; $\left(-\mathrm{O}-\mathrm{O}-\right.$ ) aged used $20 \%$ prestrain at $85^{\circ} \mathrm{C}$ in air; (一 $\square-\square-$ ) aged under $200 \%$ prestrain at $85^{\circ} \mathrm{C}$ in water. stress-strain porperties of the urethane elastomers are summarized in Table II.

It is noted that for samples aged at low prestrains $(0 \%$ and $20 \%)$ the stress-strain behaviors (Figure 1 and Table II) in the three different environments were very similar. The stress-strain curves for polyurethane samples aged under low prestrains $(0 \%$ and $20 \%)$ can be divided into three distinct regions. The high Young's modulus in region I $(0-20 \%$ strain $)$

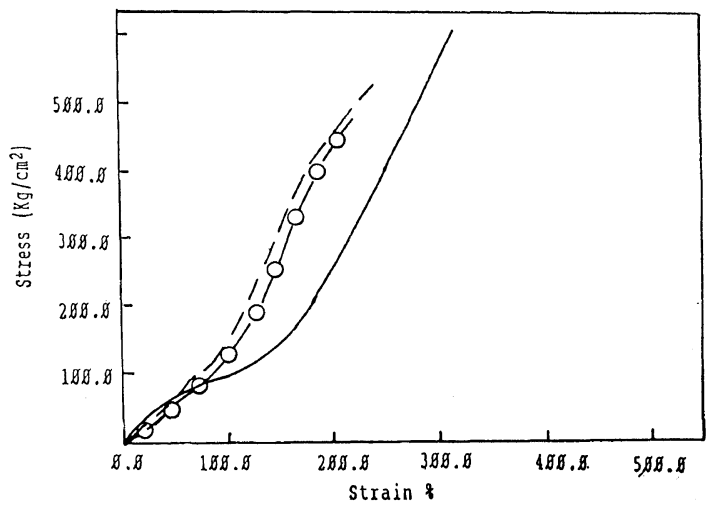

Figure 2. Stress-strain curves for polyurethane aged under $400 \%$ prestrain and in three different environments. (-) Aged $25^{\circ} \mathrm{C}$ in air; (--) aged at $85^{\circ} \mathrm{C}$ in air; aged at $(-\mathrm{O}-\mathrm{O}-) 85^{\circ} \mathrm{C}$ in water.

Table II. Mechanical properties of PU aged in various environments

\begin{tabular}{|c|c|c|c|c|c|c|}
\hline Prestrain & $\begin{array}{l}\text { Tensile stress } \\
\text { at } 20 \% \text { strain }\end{array}$ & $\begin{array}{l}\text { Tensile stress } \\
\text { at } 100 \% \text { strain }\end{array}$ & $\begin{array}{l}\text { Tensile stress } \\
\text { at } 200 \% \text { strain }\end{array}$ & $\begin{array}{c}\text { Tensile stress } \\
\text { at break }\end{array}$ & $\begin{array}{c}\text { Elongation } \\
\text { at break }\end{array}$ & $\begin{array}{l}\text { Initial Young's } \\
\text { modulus }\end{array}$ \\
\hline$\%$ & $\mathrm{~kg} \mathrm{~cm}^{-2}$ & $\mathrm{~kg} \mathrm{~cm}^{-2}$ & $\mathrm{~kg} \mathrm{~cm}^{-2}$ & $\mathrm{~kg} \mathrm{~cm}^{-2}$ & $\%$ & $\mathrm{~kg} \mathrm{~cm}^{-2}$ \\
\hline \multicolumn{7}{|c|}{$25^{\circ} \mathrm{C} / \mathrm{air} / 2$ days } \\
\hline 0 & 110.4 & 187.6 & 287.0 & 583.0 & 430 & 758.5 \\
\hline 20 & 99.4 & 187.7 & 292.5 & 589.0 & 410 & 625.5 \\
\hline 200 & 52.4 & 157.3 & 328.4 & 593.0 & 350 & 320.6 \\
\hline 400 & 33.1 & 99.4 & 231.8 & 614.0 & 315 & 180.0 \\
\hline \multicolumn{7}{|c|}{$85^{\circ} \mathrm{C} /$ air $/ 2$ days } \\
\hline 0 & 91.1 & 182.1 & 276.0 & 575.0 & 425 & 551.3 \\
\hline 20 & 88.3 & 198.7 & 314.6 & 574.0 & 395 & 500.4 \\
\hline 200 & 35.9 & 253.9 & 436.0 & 560.0 & 265 & 187.7 \\
\hline 400 & 27.6 & 156.1 & 447.0 & 523.0 & 250 & 146.6 \\
\hline \multicolumn{7}{|c|}{$85^{\circ} \mathrm{C} /$ water $/ 2$ days } \\
\hline 0 & 102.1 & 184.0 & 281.5 & 573.0 & 425 & 586.5 \\
\hline 20 & 74.5 & 193.2 & 314.6 & 558.0 & 390 & 412.4 \\
\hline 200 & 27.6 & 215.3 & 405.7 & 528.0 & 260 & 164.2 \\
\hline 400 & 22.1 & 124.2 & 430.5 & 479.0 & 220 & 125.1 \\
\hline
\end{tabular}


is due to the elastic deformation of the soft segment domain. At higher elongations, in region II ( $20-200 \%$ strain), rupturing of the hydrogen bonding of the short range hard segments occurred. This event may then lead to molecular slippage, chain disentanglement, and phase mixing. As the elongation increased, the soft segment molecules moved from transverse to parallel to the draw direction which induced crystallization. By completing the crystallite orientation, the polymer matrix becomes brittle and the stress again rises rapidly with increasing elongation ( $>200 \%$ strain, region III). Comparing the stress-strain curves of samples aged under $20 \%$ prestrain with those aged without prestrain, the stress was slightly higher in the case of strain being higher than $100 \%$ for samples aged under $20 \%$ prestrain that those aged without prestrain. This phenomenon could be due to the crystallization of soft segments aged under $20 \%$ prestrain.

However, for samples aged under highly prestrain $(200 \%$ and $400 \%$ prestrain), the stress-strain curves (Figures 1 and 2 and Table II) were quite different from those aged under low prestrain $(0 \%$ and $20 \%)$ as shown by the stress-strain data (Table II). The data indicated that the samples aged under a higher prestrain had a lower initial slope (Young's modulus) and a lower elongation at break. For the samples aged under a low prestrain, the stressstrain curves of different aging environments were very similar; while the shape of the stress-strain curves for samples aged under a high prestrain strongly depended upon the aging temperature and environment. Aging under a high prestrain, when the aging temperature was increased, the samples had higher stress in the high strain region (strain higher than $70 \%$ ) and lower stress was found in the low strain region of the stress-strain data (Table II). Comparing the stress-strain data of polyurethane elastomers aged at $85^{\circ} \mathrm{C}$ in air and $85^{\circ} \mathrm{C}$ in water, we also found that the stress was lower over whole range of strain for samples aged at $85^{\circ} \mathrm{C}$ in water.
For samples aged in the same environments but with various prestrains, the stress-strain data showed an increase in brittleness as aging prestrain was increased. This phenomenon may be due to the fact that at higher prestrain complete orientation of the hard segments parallel to the draw direction caused an increase in the degree of crystallinity of the hard segments and brittleness (as shown by the DSC data in the following sections). From Table II, we also noticed that the stress at break increased with increasing prestrain for samples aged at room temperature. However, the stress at break decreased with increasing prestrain for samples aged at higher temperatures. The samples aged at a high temperature also exhibited a lowering Young's modulus with increasing aging prestrain. The behaviors of lower Young's modulus and stress at break of stress-strain measurement for urethanes aged under a high prestrain and high temperature may be due to the chain scission of the ester linkage in the soft segments (as shown by the FTIR data in the following sections).

In the following sections, DSC data demonstrated the variations of morphology of polyurethanes aged under various conditions and FTIR results showed the evidence of the degradation of polyester $\mathrm{C}-\mathrm{O}-\mathrm{C}$ bonds for urethanes aged under a high prestrain and at higher temperature.

\section{DSC Analysis}

The DSC curves of pure soft segment polymer (high molecular weight PTAd) and pure hard segment (copolymers of BDO and MDI) which were aged without prestrain at $25^{\circ} \mathrm{C}$ in air are shown in Figure 3. The positions of the DSC endotherms and thermal transitions are listed in Table III. As indicated in Figure 3 and Table III, the glass transition temperature $\left(T_{\mathrm{g}_{1}}\right)$ and melting endothermal $\left(T_{\mathrm{m}_{1}}\right)$ were around $-51^{\circ} \mathrm{C}$ and $48^{\circ} \mathrm{C}$ respectively. The small endotherm due to short range order hydrogen bonding $\left(I_{2}\right)^{36}$ and the melting endotherm of microcrystalline domain $\left(T_{\mathrm{m}_{2}}\right)$ 
were around $66^{\circ} \mathrm{C}$ and $170-220^{\circ} \mathrm{C}$ respectively.

Typical DSC curves of the aged urethane samples under various prestrains are shown in Figure 4 for the aging conditions of $25^{\circ} \mathrm{C}$ in air with $200 \%$ and $400 \%$ prestrain, $85^{\circ} \mathrm{C}$ in air with $0 \%$ prestrain, and $85^{\circ} \mathrm{C}$ in water with $20 \%$

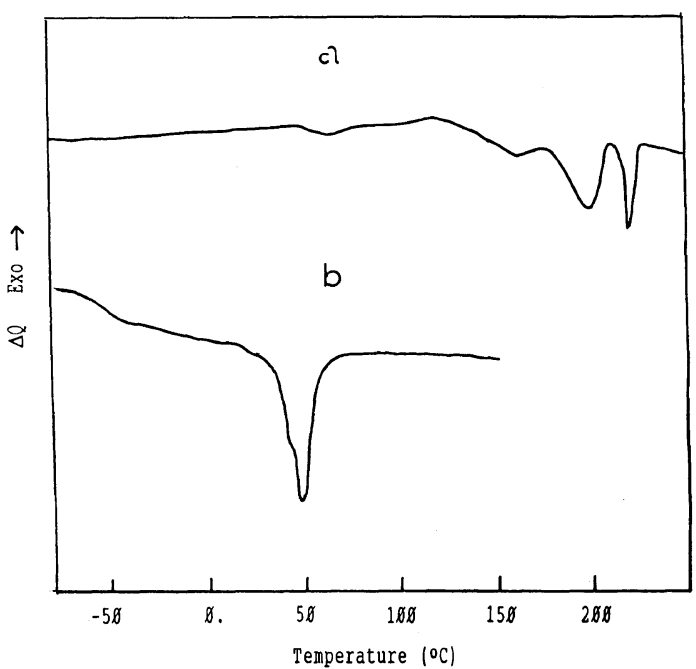

Figure 3. DSC curves of (a) pure hard segment (copolymer of BDO and MDI); (b) pure PTAd $\left(M_{n}=\right.$ $1.8 \times 10^{4}$ and $\left.M_{w} / M_{n}=2.1\right)$. prestrain. The samples were strained for two days prior to the DSC experiments. Table III lists the position of the DSC endotherms and the thermal transitions of the prestrained samples aged under various environments. The uncertainty associated with each temperature

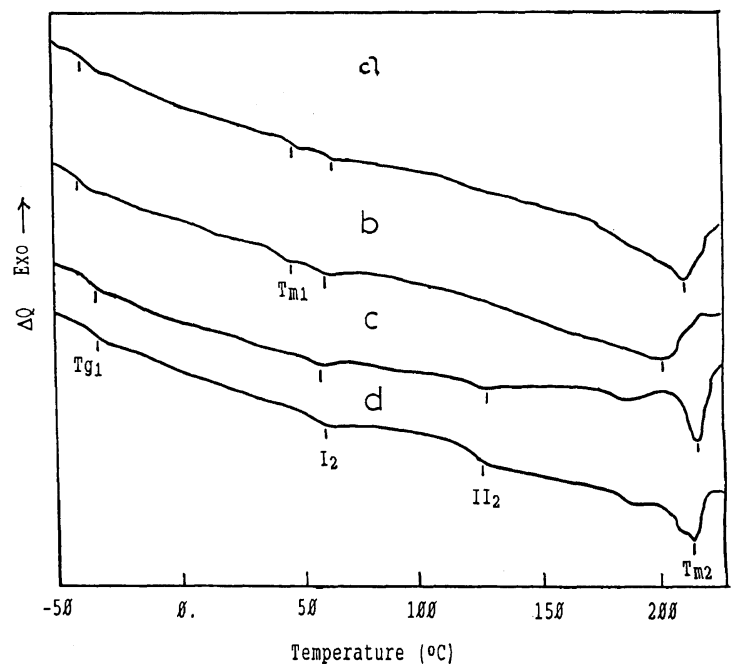

Figure 4. DSC curves of polyurethanes aged under: (a) $200 \%$ prestrain at $25^{\circ} \mathrm{C}$ in air; (b) $400 \%$ prestrain at $25^{\circ} \mathrm{C}$ in air; (c) $0 \%$ prestrain at $85^{\circ} \mathrm{C}$ in air; and (d) $20 \%$ prestrain at $85^{\circ} \mathrm{C}$ in water.

Table III. Thermal properties of aged polyurethanes

\begin{tabular}{|c|c|c|c|c|c|c|}
\hline Prestrain & $T_{\mathrm{g}_{1}} /{ }^{\circ} \mathrm{C}$ & $T_{\mathrm{m}_{1}} /{ }^{\circ} \mathrm{C}$ & $\mathrm{I}_{2} /{ }^{\circ} \mathrm{C}$ & $\mathrm{II}_{2} /{ }^{\circ} \mathrm{C}$ & $T_{\mathbf{m}_{2}} /{ }^{\circ} \mathrm{C}$ & $\Delta H_{\mathrm{f}} / \mathrm{cal} \mathrm{g}^{-1}$ \\
\hline \multicolumn{7}{|c|}{$\mathrm{PU} / 25^{\circ} \mathrm{C} /$ air $/ 2$ days } \\
\hline $0 \%$ & -33 & - & 65 & - & 210 & 8.09 \\
\hline $20 \%$ & -36 & - & 63 & - & 210 & 8.79 \\
\hline $200 \%$ & -37 & 45 & 65 & - & 211 & 9.66 \\
\hline $400 \%$ & -39 & 46 & 62 & - & 203 & 11.07 \\
\hline \multicolumn{7}{|c|}{$\mathrm{PU} / 85^{\circ} / \mathrm{air} / 2$ days } \\
\hline $0 \%$ & -32 & - & 57 & 125 & 214 & 7.80 \\
\hline $20 \%$ & -33 & - & 58 & 123 & 210 & 8.95 \\
\hline $200 \%$ & -33 & - & - & - & 209 & 9.60 \\
\hline $400 \%$ & -34 & - & - & - & 210 & 10.84 \\
\hline \multicolumn{7}{|c|}{$\mathrm{PU} / 85^{\circ} \mathrm{C} /$ water $/ 2$ days } \\
\hline $0 \%$ & -30 & - & 60 & 125 & 210 & 7.66 \\
\hline $20 \%$ & -32 & - & 60 & 124 & 211 & 8.94 \\
\hline $200 \%$ & -33 & - & - & - & 210 & 9.24 \\
\hline $400 \%$ & -33 & - & - & - & 202 & 10.60 \\
\hline \multicolumn{7}{|c|}{ PTAd $\left(M_{n}=1.8 \times 10^{4}\right) / 25^{\circ} \mathrm{C} /$ air $/ 2$ days } \\
\hline $0 \%$ & -51 & 48 & - & - & - & \\
\hline \multicolumn{7}{|c|}{ Pure Hard Segment $/ 25^{\circ} \mathrm{C} /$ air $/ 2$ day } \\
\hline & - & - & 66 & - & 198 and 217 & \\
\hline
\end{tabular}


is approximately $\pm 2{ }^{\circ} \mathrm{C}$.

The prestrained urethane samples, aged under ambient conditions $\left(25^{\circ} \mathrm{C}\right.$ in air) generally exhibited three transition regions detected by DSC as shown in Figure 4 and Table III. Between $-30^{\circ} \mathrm{C}$ and $-40^{\circ} \mathrm{C}$, a sharp increase in the specific heat occurs, and is due to the soft-segment glass transition $\left(T_{\mathrm{g}_{1}}\right)$. The $T_{\mathrm{g}}$ of the soft segment domains, is an indicator for the degree of phase separation. When there were hard segments dispersed in the soft domains, the $T_{\mathrm{g}_{1}}$ was raised. It is found that $T_{\mathrm{g}_{1}}$ shifts slightly to lower temperatures when the samples were subjected to higher prestrains (Table III). This implies that prestrain would promote phase demixing of hard and soft segments favoring pure soft domains. Between $60^{\circ} \mathrm{C}$ and $65^{\circ} \mathrm{C}$ a small endotherm occurs $\left(\mathrm{I}_{2}\right)$, due to the dissociation of short range ordering in the hard segment domain. ${ }^{32,36}$ For samples aged at $25^{\circ} \mathrm{C}$ and under a high prestrain ( $\geqq 200 \%$ elongation), a small endotherm appeared around $45^{\circ} \mathrm{C}$, due to the melting endotherm $\left(T_{\mathrm{m}_{1}}\right)$ of the soft segment crystallization induced by strain. The primary endotherm $\left(T_{\mathrm{m}_{2}}\right)$ was found in the third region (170$230^{\circ} \mathrm{C}$ ) with the multiple peaks, which could be the sequential melting/distruption of hardsegment domains having different degrees of organization. ${ }^{36}$ This endotherm was not affected by prestrain in this study, however, the heat of fusion, $\Delta H_{\mathrm{f}}$, increased with increasing prestrain during aging. Crystallization requires an extact arrangement of hard segments into a lattice structure and thus has a well defined temperature associated with melting. Therefore, the present data indicated that prestrain may be expected to change the shape or size of the crystalline melting peak, but not its position unless significant changes are made in crystallite size or perfection. The crystallite size increased with increasing prestrain. These different degrees of organization were developed depending upon prior thermal and processing history of the elastomers. It is noted that when the aging prestrain reached $400 \%$, the multiple melting peaks disappeared and turned into a broad endotherm.

Similar behavior of the glass transition temperature $\left(T_{\mathrm{g}_{1}}\right)$ of the soft segment, melting temperature $\left(T_{\mathrm{m}_{2}}\right)$ of the microcrystalline domain, and endotherm of hard segment $\left(\Delta H_{\mathrm{f}}\right)$ for the sample aged at $85^{\circ} \mathrm{C}$ in air as those aged at $25^{\circ} \mathrm{C}$ in air were found. (Table III and Figure 4). The $T_{\mathrm{g}_{1}}$ of the soft segment slightly decreased and the heat of fusion, $\Delta H_{\mathrm{f}}$, of microcrystalline domain increased as the prestrain increased during aging. In contrast to the prestrained samples aged at $25^{\circ} \mathrm{C}$, the $T_{\mathrm{g}_{1}}$ of the soft segments was increased by aging the samples at a higher temperature, indicating that annealing at high temperature could promote mixing of soft and hard domains and result in a higher $T_{\mathrm{g}_{1}}$. The heat of fusion, $\Delta H_{\mathrm{f}}$, of microcrystalline decreased as the aging temperature increased, suggesting the rupture of hydrogen bond in the microcrystalline domain at high temperature. Comparing to the samples aged in air at $25^{\circ} \mathrm{C}$, the other difference in the thermal behavior of samples aged at $85^{\circ} \mathrm{C}$ in air, was the appearance of an endotherm $\left(\mathrm{II}_{2}\right)$ in the $110-130^{\circ} \mathrm{C}$ range for urethane samples with low prestrains $(0 \%$ and $20 \%$ ). This endotherm might be due to the dissociation of long-range ordering hardsegment domains. ${ }^{36}$ For aging at $85^{\circ} \mathrm{C}$ with prestrain higher than $200 \%$, the endotherms of short range ordered hard segment domain $\left(\mathrm{I}_{2}\right)$ and long range ordered hard segment domain $\left(\mathrm{II}_{2}\right)$ disappeared, and the shape of the crystalline hard segment domain $\left(T_{\mathrm{m}_{2}}\right)$ were broader than those aged under lower prestrain. These data suggested that aging under high prestrain and high temperature resulted in an increase of the size of the crystalline hard domain.

The DSC data of the prestrained samples aged at $85^{\circ} \mathrm{C}$ under water were similar to those of samples aged at $85^{\circ} \mathrm{C}$ in air in the following patterns: the appearance of $\mathrm{I}_{1}$ and $\mathrm{II}_{2}$ endotherms at lower prestrains; and the disappearance of $I_{1}$ and $I_{2}$ endotherms and the 


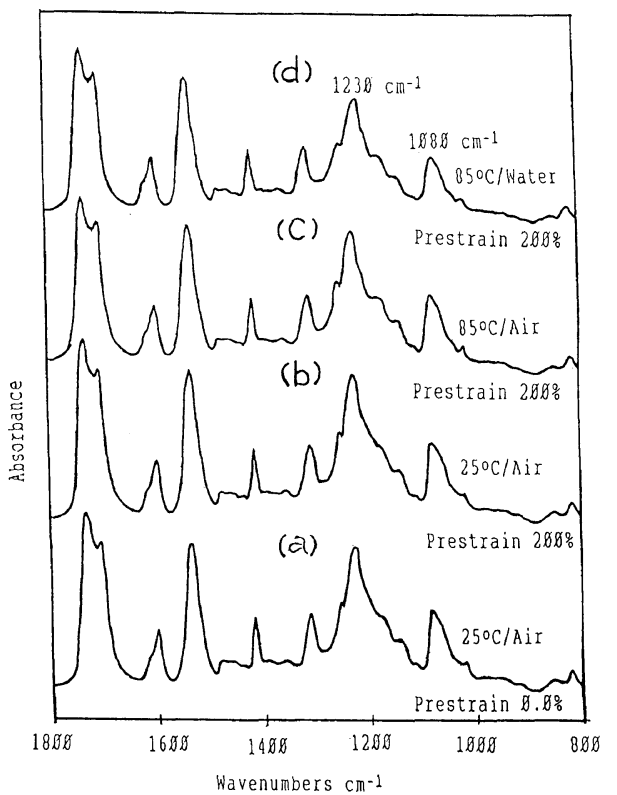

Figure 5. FTIR spectra of polyurethane aged in four different conditions. (a) $0 \%$ prestrain, $25^{\circ} \mathrm{C}$ in air; (b) $200 \%$ prestrain, $25^{\circ} \mathrm{C}$ in air; (c) $200 \%$ prestrain, $85^{\circ} \mathrm{C}$ in air; (d) $200 \%$ prestrain, $85^{\circ} \mathrm{C}$ in water.

broadening of the microcrystalline domain $\left(T_{\mathrm{m}_{2}}\right)$ in the highly prestrained samples. (Table III and Figure 4).

In general, $T_{\mathrm{g}_{1}}$ decreased with increasing aging prestrain and increased with increasing aging temperature; while $T_{\mathrm{m}_{2}}$ remained constant with increasing prestrain and aging temperature and seems not to depend on the environment that the samples were subjected to. The heat of fusion, $\Delta H_{\mathrm{f}}$, increased with increasing prestrain and decreased with increasing aging temperature.

\section{Infrared Analysis}

As shown in the previous section, the stressstrain data for urethanes aged under a high prestrain strongly depended upon the aging temperature and environment. Hence, the urethane samples aged under $200 \%$ prestrain in three different environments were investigated by FTIR. The IR spectra of $200 \%$ prestrained polyesterurethane samples aged in three environments $\left(25^{\circ} \mathrm{C}\right.$ in air, $85^{\circ} \mathrm{C}$ in air
Table IV. Absorbance of ester and urethane $\mathrm{C}-\mathrm{O}-\mathrm{C}$ stretching for PU aged at various conditions

\begin{tabular}{lccc}
\hline \multirow{2}{*}{ Aging condition } & $1250-1180$ & & $1100-1030$ \\
\cline { 2 - 2 } & $\mathrm{cm}^{-1}$ & & $\mathrm{~cm}^{-1}$ \\
\hline $25^{\circ} \mathrm{C} /$ air $/ 0 \%$ prestrain & 87.2 & & 91.4 \\
$25^{\circ} \mathrm{C} /$ air $/ 200 \%$ prestrain & 87.0 & & 91.2 \\
$85^{\circ} \mathrm{C} /$ air $/ 200 \%$ prestrain & 84.6 & & 89.1 \\
$85^{\circ} \mathrm{C} /$ water/200\% prestrain & 83.3 & & 87.1 \\
\hline
\end{tabular}

Note: The absorbance are given using the 1430-1400 $\mathrm{cm}^{-1}$ band equals 10 as a reference.

and $85^{\circ} \mathrm{C}$ in water) are presented in Figure 5. According to the IR spectra absorption band assignment by Silverstein et al., ${ }^{37}$ the very strong band that occurs at $1230 \mathrm{~cm}^{-1}$ is considered to be the ester $\mathrm{C}-\mathrm{O}-\mathrm{C}$ unsymmetric stretching of the ester and urethane groups mixed with $\mathrm{CH}_{2}$ wagging mode. Another band appearing at $1080 \mathrm{~cm}^{-1}$ is attributed to ester $\mathrm{C}-\mathrm{O}-\mathrm{C}$ symmetric stretching of the ester and urethane groups. Table IV shows the changes of the intergrated absorption peak area (A) of the $\mathrm{C}-\mathrm{O}-\mathrm{C}$ stretching of the $200 \%$ prestrained samples aged in air and water at various temperatures, using the $1410 \mathrm{~cm}^{-1}$ band, which is a thermally stable $\mathrm{C}-\mathrm{C}$ stretching in the benzene ring as a reference peak. The wateraged samples were found to be more degraded than the air-aged samples, especially at higher temperature.

\section{CONCLUSION}

Very similar stress-strain curves of urethane elastomers aged under low presstrains $(0 \%$ and $20 \%)$ in three environments $\left(25^{\circ} \mathrm{C}\right.$ in air, $85^{\circ} \mathrm{C}$ in air, and $85^{\circ} \mathrm{C}$ in water) were obtained. However, for urethane elastomers aged under high prestrains $(200 \%$ and $400 \%)$, the behavior of stress-strain curves was strongly influenced by the aging environments. Aging at a high prestrain, with increasing aging temperature caused a decrease in the initial slope of stress- 
strain measurement, and an increase in brittleness of urethanes. Aging at a high temperature also resulted in decreases both in tensile stress and elongation at break. Comparing samples aged at a high temperature but under various prestrains, we found that aging at a higher prestrain resulted in lowering the initial slope of stress-strain curve, stress at break, and elongation at break. FTIR experimental data revealed the degradation of ester $\mathrm{C}-\mathrm{O}-\mathrm{C}$ bond for polyurethane elastomers aged at a high temperature with a high prestrain, especially under water which may be the reason for the lowering of the initial slope of the stress-strain curve and the tensile stress at break and elongation at break. DSC experimental results demonstrated the increase in microcrystalline domain induced by increasing prestrain during aging. The crystallization of urethane elastomers induced by prestrain during aging leads to the behavior of brittleness. The FTIR experimental results also revealed that more degradation of ester $\mathrm{C}-\mathrm{O}-\mathrm{C}$ bond for urethane elastomers aged under water than aged in air which caused the behavior of lower stress over the whole range of strain of stress-strain curves for urethane elastomers aged under water at $85^{\circ} \mathrm{C}$ than under air at $85^{\circ} \mathrm{C}$.

\section{REFERENCES}

1. S. L. Copper and A. V. Tobolsky, J. Appl. Polym. Soc., 10, 1837 (1966).

2. T. K. Kwei, J. Appl. Polym. Sci., 27, 2891 (1982).

3. D. S. Huh and S. C. Cooper, Polym. Eng. Sci., 11, 369 (1971).

4. C. E. Wilkes and C. S. Yusek, J. Macromol. Sci. Phys., B7, 157 (1973).

5. (a) G. G. Seefried, Jr., J. V. Koleske, and F. E. Critchfield, J. Appl. Polym. Sci., 19, 2493 (1975); (b) ibid., 3185.

6. G. W. Miller and J. H. Saunders, J. Polym. Sci., A-18, 1923 (1970).

7. S. Abouzahr and G. L. Wilkes, J. Appl. Polym. Sci., 29, 2695 (1984).

8. J. A. Miller, S. B. Lin, K. K. S. Hwang, K. S. Wu, P. E. Gibson, and S. L. Cooper, Macromolecules, 18, 32 (1985).
9. R. W. Seymour and S. L. Cooper, Macromolecules, 6, 48 (1973).

10. J. T. Koberstein and A. F. Galambos, Macromolecules, 25, 5618 (1992).

11. J. T. Koberstein, A. F. Galambos, and L. M. Leung, Macromolecules, 25, 6195 (1992).

12. J. T. Koberstein and L. M. Leung, Macromolecules, 25, 6205 (1992).

13. C. S. Paik Sung, C. B. Hu, and C. S. Wu, Macromolecules, 13, 111 (1980).

14. J. A. Miller and S. L. Copper, J. Polym. Sci., Polym. Phys. Ed., 23, 1065 (1985).

15. L. M. Leung and J. T. Koberstein, Macromolecules, 19, 706 (1986).

16. J. T. Koberstein and I. Gancarz, J. Polym. Sci., Polym. Phys. Ed., 24, 2487 (1986).

17. J. C. West and S. L. Cooper, J. Polym. Sci., Polym. Symp., 60, 27 (1977).

18. M. M. Coleman, K. H. Lee, D. J. Skrovanek, and D. C. Painter, Macromolecules, 19, 2149 (1986).

19. G. L. Wilkes, S. L. Samuel, and R. G. Crystal, J. Macromol. Sci.-Phys., B10, 203 (1974).

20. J. Foka and H. Janik, Polym. Eng. Sci., 29, 113 (1989).

21. R. J. Athey, Rubber Age, 96, 705 (1965).

22. G. Magnu, R. A. Dunleavy, and F. E. Critchfield, Rubber Chem. Tech., 39, 1328 (1966).

23. F. H. Gahimer and F. W. Nieske, J. Elastoplastics, 1, 26 (1967).

24. H. Y. Bonk and A. A. Sardanopoli, J. Elastoplastics, 4, 157 (1971).

25. A. Sign and R. Saxon, Rubber Age, 107, 53 (1975).

26. C. R. Desper, N. S. Schneider, J. P. Jasinski, and J. S. Lin, Macromolecules, 18, 2755 (1985).

27. R. W. Seymour, A. E. Allegrazza, and S. L. Copper, Macromolecules, 6, 896 (1973).

28. A. E. Allegrazza, R. W. Seymour, H. N. Ny, and S. L. Copper, Polymer, 15, 433 (1974).

29. G. M. Estes, R. W. Seymour, and S. L. Cooper, Macromolecules, 4, 452 (1971).

30. C. F. Wilkes and C. S. Yusek, J. Macromole. Sci.-Phys., B7, 157 (1973).

31. R. Bonart, J. Macromol. Sci-Phys., B2, 115 (1968).

32. C. B. Wang and S. L. Cooper, Macromolecules, 16, 775 (1983).

33. C. S. P. Sung, T. W. Smith, and N. H. Sung, Macromolecules, 13, 117 (1980).

34. C. S. P. Sung, T. W. Smith, C. B. Hu, and N-H. Sung, Macromolecules, 12, 538 (1979).

35. L. L. Harrell, Macromolecules, 2, 607 (1969).

36. T. R. Hesketh, J. W. C. van Bogart, and S. L. Cooper, Polym. Eng. Sci., 20, 190 (1980).

37. R. M. Silverstein, G. Clayton, and T. C. Morrill, in "Spectrometric Identification of Organic Compounds," 4th ed., John Wiley \& Sons, New York, 1981. 